\title{
Synthesis of 8-Hydroxyquinoline/exchanged montmorillonite hybrids: Sorption, Luminescence and Thermal stability studies
}

\author{
Besma Mellah *, Thouraya Turki, Wafa Chammam and Ezzedine Srasra \\ Laboratory of Composite Materials and Clay Minerals National Center of Researches in Material Sciences, \\ Technopôle Borj Cédria, Tunisia
}

\begin{abstract}
Hybrids (H) prepared from 8-Hydroxyquinoline (8-HQ, "oxine") and exchanged montmorillonites (Na(I)-, Zn(II)- and Fe(III)-Mont) have been synthesized using solid-solid reactions at room temperature. The characterization of these hybrids by PPXRD has shown that the interlayer spaces swell (from 0.22 to $1.10 \AA$ of $\mathrm{d}_{001}$ differences) after the inclusion of 8-HQ due to its complexation with the cations present. In the IR spectra, new bands corresponding to 8-HQ groups, appear in the regions $1244-1608 \mathrm{~cm}^{-1}$ and $574-826 \mathrm{~cm}^{-1}$. DSC measurement has shown the hybrids to be more stable than the precursor montmorillonites, 8-HQ and the simple metal oxinates. Zeta potential measurement on suspensions of the hybrids showed them to be negatively charged over the whole $\mathrm{pH}$ range $(\mathrm{pH}=2-10)$. As an application of our elaborated hybrids, sorption of the cationic dye methylene blue $\mathrm{MB}\left(\mathrm{C}_{\mathrm{MB}}=200 \mathrm{mg} . \mathrm{L}^{-1}\right)$ by the $\mathrm{Na}(\mathrm{I})-, \mathrm{Zn}(\mathrm{II})$ - and $\mathrm{Fe}(\mathrm{III})$-hybrids has been found to be rapid for the first two. At the same time, for the Fe(III) species, one month of sedimentation was required to adsorb $87 \%$ of MB. The structural characterization of multi-hybrids $\mathrm{MH}(\mathrm{H}+\mathrm{MB})$ by PXRD has shown a shift of $\mathrm{d}_{001}$ to higher values (Na-MH: $15.32 \AA$; Zn-MH: $16.61 \AA$; Fe-MH: $16.99 \AA$ ), signifying the intercalation of MB into interlayer spaces.
\end{abstract}

Keywords: 8-Hydroxyquinoline; Sorption; Montmorillonite; Methylene Blue Dye; Multi-Hybrid.

\section{Introduction}

Technological progress, coupled with population growth, has meant that demand for clean water has increased rapidly. Unfortunately, natural processes for wastewater purification have become inadequate because of the volume of liquid, solid or gaseous toxic discharges. Both chemical and physical methods have been applied to remove organic effluents from industrial wastewater. Montmorillonite is the basis of the most frequently used chemical processes due to its abundance in nature, low-cost, activity as a host-guest layered material, high surface area and cation exchange capacity ${ }^{1-5}$. Sorption on montmorillonite finds Application in textile, leather, cosmetics, plastics and paper industries where dyes are used. Dyes can cause harmful effects on human health such as nausea, vomiting, heart palpitation and eye/skin carcinogenic irritation 6,7 . To achieve efficient recovery of water with the desired quality, a careful selection of sorbent is of vital importance.

The sorption on montmorillonite is a complex process in which pollutants may be adsorbed on the surface or by intercalation between silicate layers. Both physisorption and weak chemisorption are considered to be involved. Various parameters determining sorption efficiency include the nature of

*Corresponding author: Besma Mellah

Email address: mellahbesma@yahoo.fr

DOI: http://dx.doi.org/10.13171/mjc10502005201345bm the smectite, pollutant and experimental conditions ( $\mathrm{pH}$, concentration of pollutants, contact time, particle size, stirring rate and temperature) ${ }^{1,3-10}$. As natural montmorillonites are hydrophilic, they require modification to bind hydrophobic organic compounds. Increase of their interplanar spacing, surface area and hydrophobicity have been shown to make them useful in, for example, sewage treatment. 8-hydroxyquinoline(8-HQ) has been reported to be an effective intercalant into the interplanar space of montmorillonites either via liquid extraction from aqueous solution ${ }^{11,12}$ or via solid-solid reaction ${ }^{13-15}$. It has been demonstrated that the sorption of 8-HQ by metal-ion-exchanged montmorillonites occurs through its complexation with the cations found between silicate layers. Applications of some such complexes have been studied earlier but only regarding their luminescence ${ }^{16}$. A blue shift of emission and a decrease of emission intensities of $\mathrm{Mq}_{3}$-smectites $\left(\mathrm{q}=\right.$ oxinate anion; $\mathrm{M}=\mathrm{Ln}^{3+}, \mathrm{Ga}^{3+}$ and $\mathrm{Al}^{3+}$ ) was observed as the cation size decreased.

In current work, preparation of hybrids based on 8-hydroxyquinoline and exchanged montmorillonites (Na(I)-, Zn(II)- and Fe(III)-Mont) has been realized by the solid-solid reaction. The choice of this procedure is due to its efficiency, short reaction time

Received February 15, 2020 Accepted March 10, 2020 Published May 20, 2020 
and "green" character. The structural and composition analysis of hybrids was performed by FT-IR, PXRD, SEM, and DSC techniques. Then, the treatment of an aqueous solution of methylene blue $\mathrm{MB}\left(\mathrm{C}_{\mathrm{MB}}=200\right.$ mg. $\left.\mathrm{L}^{-1}\right)$ has been realized. The aim of this part is to study the effect of complex compositions on the sorption of MB. The discoloration of MB solution has been followed by UV-visible spectrophotometer at two different times of sedimentation.

\section{Experimental}

\subsection{Materials}

The montmorillonite clay used in this study was from north-east Tunisia. Its characterization, purification and cation exchange behavior have been described in our previous work ${ }^{12}$. Natural clay, cation-exchanged montmorillonites (M-Mont) and various 8HQ/Montmorillonite hybrids were characterized by PPXRD on a Panalytical diffractometer using $\mathrm{Cu} \mathrm{K} \alpha$ radiation. Composition analysis was conducted by $\mathrm{X}$ ray fluorescence spectroscopy (XRF S8Tiger 3KW). The FTIR spectra were recorded on a PerkinElmer FT-IR/FIR Spectrometer Frontier in the scanning region 4000-400 $\mathrm{cm}^{-1}$. The spectrofluorometric analysis was carried out using a Perkin Elmer LS55 fluorescence spectrometer in which the solid samples were introduced into an optical path quartz vessel $1=$ $0.2 \mathrm{~cm}$. The excitation wavelength was $\lambda_{\text {ext }}=360 \mathrm{~nm}$ and emission were monitored between 300 and 700 $\mathrm{nm}$. The Zeta potential (ZP) measurement has been recorded by Malvern Zetasizer Nano-ZS and followed at $\mathrm{pH}=2,4,6,8$ and 10. DSC measurements were performed on an Erhard-Mettler instrument in the temperature range of $25-600^{\circ} \mathrm{C}$ at a heating rate of $10^{\circ} \mathrm{C} \cdot \mathrm{min}^{-1}$. An aluminum crucible with a perforated cover was used as the sample holder. The sorption of the dye was followed by visible spectrophotometry (Perkin-Elmer).

\subsection{Preparation of exchanged montmorillonites} The $\mathrm{Zn}(\mathrm{II})$-Mont was obtained by the exchange of $\mathrm{Na}^{+}$with $\mathrm{Zn}^{2+}$ as described in our previous work ${ }^{12}$. The Fe(III)-Mont was obtained by mechanical agitation of $10 \mathrm{~g}$ of Na-Mont in an aqueous solution of $\mathrm{FeCl}_{3}$ (1M) (Aldrich) over 24h at room temperature. The solid present was recovered by centrifugation and subjected to a second treatment with fresh $\mathrm{Fe}(\mathrm{III})$ solution. The solid then again collected by centrifugation was washed with water until free of chloride (checked by $\mathrm{AgNO}_{3}$ solution). The cation exchange capacities (CEC) were measured by the copper ethylenediamine method ${ }^{17}$. CEC expresses the ability of the smectite to exchange the interlayered cations. Table 2 gives the CEC of each exchanged montmorillonite and the natural clay.

\subsection{Preparation of hybrids}

The sorption of $8-\mathrm{HQ}\left(\mathrm{C}_{9} \mathrm{H}_{7} \mathrm{NO}, \mathrm{MW}=145.16 \mathrm{~g} \cdot \mathrm{mol}^{-}\right.$ $\left.{ }^{1}\right)$ by the exchanged montmorillonites was achieved via solid-solid reaction. $2 \mathrm{~g}$ of each exchanged clay was ground manually with $0.3 \mathrm{~g}$ of 8 -HQ for $3 \mathrm{~min}$ at room temperature. Then, products were then washed with ethanol until no absorption due to 8-HQ was detectable in the UV spectrum of the wash.

\subsection{Dye sorption experiments}

The removal of methylene blue $\mathrm{MB}\left(\mathrm{C}_{16} \mathrm{H}_{18} \mathrm{ClN}_{3} \mathrm{~S}\right.$, $\left.\mathrm{MW}=319.86 \mathrm{~g} \cdot \mathrm{mol}^{-1}\right)$ from aqueous solutions was studied using our hybrids $(\mathrm{H})$ at room temperature. 0.1 $\mathrm{g}$ of each hybrid (8-HQ/Na(I)-, Zn(II)- and Fe(III)Mont) was mechanically stirred in the presence of an aqueous solution of MB (200 mg L L $\left.\mathrm{m}^{-1}\right)$ for $2 \mathrm{~h}$. Absorbance measurements determined the change of the dye concentration in the supernatant solution at $665 \mathrm{~nm}$ after 1 day and 1 month of sedimentation. The adsorption yield of $\mathrm{MB}(\mathrm{T}(\%))$ on the hybrids was calculated through the equation (1).

$\mathrm{T}=\frac{(\mathrm{Ci}-\mathrm{Cf})}{\mathrm{Ci}} \times 100 \%$

Where $C_{i}$ and $C_{f}$ are respectively the initial and the final concentration of $\mathrm{MB}$.

\section{Results and discussion}

\subsection{Characterization of exchanged montmorillonites}

The CEC (Table 1) of Na(I)-Mont and Zn(II)-Mont are quite similar and higher than natural clay. However, the CEC of Fe(III)-Mont has visibly decreased which could be assigned to the hydroxylation of ferric ions, as reported by Manjanna ${ }^{18}$.

Table 1. Cation exchange capacities (CEC).

\begin{tabular}{|c|c|c|c|c|}
\hline Samples & Natural clay & Na(I)-Mont & Zn(II)-Mont & Fe(III)-Mont \\
\hline $\begin{array}{c}\text { CEC } \\
\text { (meq / 100g of hydrated clay) }\end{array}$ & $66^{12}$ & $84^{12}$ & $81^{12}$ & 16 \\
\hline
\end{tabular}

The XRD diffractograms of $\mathrm{Na}(\mathrm{I})-, \mathrm{Zn}(\mathrm{II})$ - and $\mathrm{Fe}(\mathrm{III})-\mathrm{Mont}$ show a shift of the interlayer spacing $\mathrm{d}_{001}$ from $14.89 \AA$ in natural clay to $12.36 \AA$ in exchanged $\mathrm{Na}(\mathrm{I})$-Mont. Substitution of $\mathrm{Na}(\mathrm{I})$ by $\mathrm{Zn}(\mathrm{II})$ or $\mathrm{Fe}$ (III) increases the interlayer spacing from $12.36 \AA$ to $15.11 \AA$ or $14.86 \AA$, respectively. Furthermore, new peaks (at 5.26, 2.55, 2.28, 2.13 and $1.38 \AA$ ) were observed in the diffractogram of Fe(III)-
Mont. These peaks have been assigned to $\mathrm{FeO}(\mathrm{OH})$, confirming from one side the results of Manjanna et al. ${ }^{18}$ and explaining from another side the decrease of CEC (=16) in Fe(III)-Mont.

The FTIR spectrum shows the disappearance of the absorption bands corresponding to both carbonate $\left(1420,871\right.$ and $\left.710 \mathrm{~cm}^{-1}\right)$ and quartz $(797,780$ and $695 \mathrm{~cm}^{-1}$ ) after purification ${ }^{12}$ of natural clay. In the 
spectrum of $\mathrm{Fe}(\mathrm{III})-\mathrm{Mont}$, weak bands under $700 \mathrm{~cm}^{-1}$ were evident. They could be assigned to the $\mathrm{Fe}-\mathrm{O}$ stretch as described in the literature ${ }^{19}$. The $\mathrm{OH}$ stretching $\left(3622 \mathrm{~cm}^{-1}\right)$ and $\mathrm{Al}-\mathrm{O}-\mathrm{H}$ bending $\left(910 \mathrm{~cm}^{-1}\right)$ vibrations of $\mathrm{Al}-\mathrm{OH}$ units are consistent with the dioctahedral structure of montmorillonites. Furthermore, the strong bands of vibration corresponding to the - $\mathrm{OH}$ groups of interlayered water appear at $3455 \mathrm{~cm}^{-1}$ and those of deformation at 1640 $\mathrm{cm}^{-1}$. A large and intense band at $1000 \mathrm{~cm}^{-1}$, was assigned to $\mathrm{Si}-\mathrm{O}^{20}$ stretching while the deformation of Si-O-Si was observed as a broadband at $520 \mathrm{~cm}^{-1}$. The composition of $\mathrm{Na}(\mathrm{I})$-Mont as determined by $\mathrm{XRF}$ analysis is given in Table 1. The bulk components ( $\mathrm{Al}$ and $\mathrm{Si}$ ) are present in a ratio consistent with that of the montmorillonite structure. It has shown that $\mathrm{SiO}_{2}$ is the major component, and the second is $\mathrm{Al}_{2} \mathrm{O}_{3}$. The quantity of the tetrahedral sheet $\mathrm{T}: \mathrm{SiO}_{2}(38.16 \%)$ is almost double than the octahedral sheet $\mathrm{O}: \mathrm{Al}_{2} \mathrm{O}_{3}(17.18 \%)$, which confirms the montmorillonite structure $(\mathrm{T}: \mathrm{O}=2: 1)$ of our clay. The minor elements are $\mathrm{Mg}(2.39 \%$ as $\mathrm{MgO}), \mathrm{K}$ $\left(1.01 \%\right.$ as $\left.\mathrm{K}_{2} \mathrm{O}\right), \mathrm{Ca}(3.28 \%$ as $\mathrm{CaO}), \mathrm{Fe}(5.28 \%$ as $\left.\mathrm{Fe}_{2} \mathrm{O}_{3}\right)$ and $\mathrm{Ti}\left(0.68 \%\right.$ as $\left.\mathrm{TiO}_{2}\right)$. The exchanged cation $\mathrm{Na}(\mathrm{I})$ is present as $\mathrm{NaO}_{2}$ with a proportion of $7.34 \%$. The trace elements of the Na-Mont are $\mathrm{Zn}, \mathrm{P}, \mathrm{S}, \mathrm{Cr}$, $\mathrm{Mn}$ and Sr.

Table 2. Composition of $\mathrm{Na}(\mathrm{I})-\mathrm{Mont}(\%)$.

\begin{tabular}{|c|c|c|c|c|c|c|c|c|c|c|c|c|c|c|}
\hline $\mathrm{Na}_{2} \mathrm{O}$ & $\mathrm{MgO}$ & $\mathrm{Al}_{2} \mathrm{O}_{3}$ & $\mathrm{SiO}_{2}$ & $\mathrm{P}_{2} \mathrm{O}_{5}$ & $\mathrm{SO}_{3}$ & $\mathrm{~K}_{2} \mathrm{O}$ & $\mathrm{CaO}$ & $\mathrm{TiO}_{2}$ & $\mathrm{Cr}_{2} \mathrm{O}_{3}$ & $\mathrm{Mn}_{2} \mathrm{O}_{3}$ & $\mathrm{Fe}_{2} \mathrm{O}_{3}$ & $\mathrm{ZnO}$ & $\mathrm{SrO}$ & $\mathrm{Sum}$ \\
\hline 7.34 & 2.39 & 17.18 & 38.16 & 0.21 & 0.03 & 1.01 & 3.28 & 0.68 & 0.02 & 0.02 & 5.28 & 0.01 & 0.03 & $\mathbf{9 9 . 6 4}$ \\
\hline
\end{tabular}

The images of $\mathrm{Na}(\mathrm{I}), \mathrm{Zn}(\mathrm{II})$ - and $\mathrm{Fe}(\mathrm{III})-\mathrm{Mont}$ recorded by the Scanning Electron Microscope are shown in Figure 1. According to the enlargement of $50 \mu \mathrm{m}$ in this surface area, we notice the layered and irregularity of the structure of particles, having a tendency slightly to circular shape, with different sizes. The particles of Fe(III)-Mont have better continuity and are significantly smaller than $\mathrm{Na}(\mathrm{I})$ and $\mathrm{Zn}(\mathrm{II})-$ Mont.

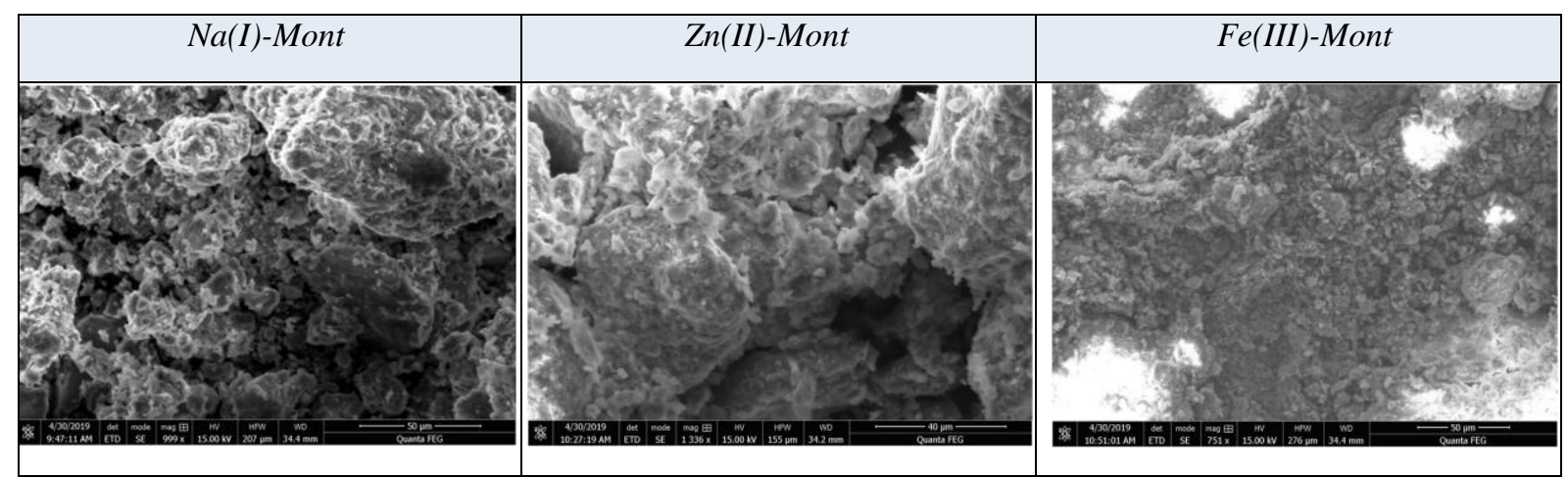

Figure 1. Images of $\mathrm{Na}(\mathrm{I}), \mathrm{Zn}(\mathrm{II})$ - and $\mathrm{Fe}(\mathrm{III})$-Mont recorded by the Scanning Electron Microscope

\subsection{Characterization of 8-HQ hybrids}

Figure 2 shows evident color changes before and after interaction with 8-HQ. The green color of 8$\mathrm{HQ} / \mathrm{Zn}(\mathrm{II})-$ Mont has been observed previously after either liquid-solid extraction ${ }^{12}$ or by the solid-solid reaction ${ }^{13}$. Khaorapapong has attributed this change to a green color to the formation of the bihydrated complex in situ the montmorillonite, as the anhydrous complex is yellow. Moreover, the different colors observed with the three exchanged clays after interaction with 8-HQ have been assigned to the differences in coordination numbers and electronic structures of complexes of $\mathrm{Na}(\mathrm{I}), \mathrm{Zn}(\mathrm{II})$ and $\mathrm{Fe}(\mathrm{III})^{13,14}$
The size averages (Z-Ave) of natural clay, exchangedMont and hybrids are given in Table 3 . They show that the size of natural clay particles has decreased after its purification. In contrast, the sizes of exchanged-Mont and hybrids, respectively, have increased considerably from mono- to bi- then trivalent cation. Furthermore, the sizes of Zn-Mont and Zn-hybrid are almost 4 times higher than Na-Mont and Na-hybrid, respectively, while the sizes of Fe-Mont and Fehybrid are, respectively, nearly 6 times higher than Na-Mont and Na-hybrid. 


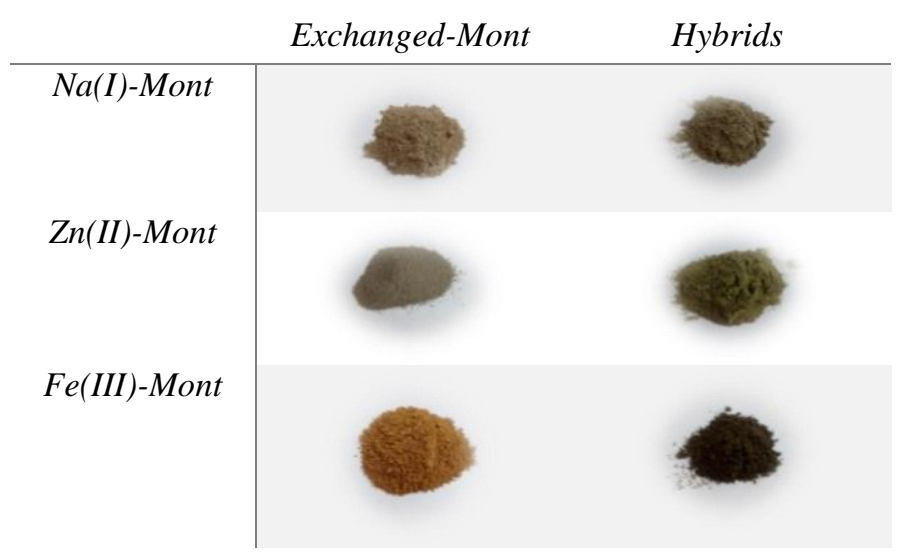

Figure 2. Color changes before and after interaction between 8-HQ and $\mathrm{Na}$ (I)-, $\mathrm{Zn}$ (II)- and $\mathrm{Fe}(\mathrm{III})$ Montmorillonites

Table 3. Size average (Z-Ave (d.nm)) of particles of natural clay, exchanged-Mont and hybrids.

\begin{tabular}{|c|c|c|c|c|c|c|c|}
\hline Samples & $\begin{array}{c}\text { Natural } \\
\text { Clay }\end{array}$ & $\begin{array}{c}\text { Na(I)- } \\
\text { Mont }\end{array}$ & $\begin{array}{c}\text { 8-HQ/Na(I)- } \\
\text { Mont }\end{array}$ & Zn(II)-Mont & $\begin{array}{c}\text { 8-HQ/Zn(II)- } \\
\text { Mont }\end{array}$ & $\begin{array}{c}\text { Fe(III)- } \\
\text { Mont }\end{array}$ & $\begin{array}{c}\text { 8-HQ/Fe(III)- } \\
\text { Mont }\end{array}$ \\
\hline $\begin{array}{c}\text { Z-Ave } \\
\text { (d.nm) }\end{array}$ & 958 & 730 & 698 & 2777 & 2786 & 4198 & 3785 \\
\hline
\end{tabular}

\subsubsection{Characterization by FTIR}

The normalized FTIR spectra of $8-\mathrm{HQ} / \mathrm{Na}(\mathrm{I})-$, $\mathrm{Zn}(\mathrm{II})-$ and $\mathrm{Fe}(\mathrm{III})$-Montmorillonite hybrids, recorded between 400 and $4000 \mathrm{~cm}^{-1}$, are presented in Figure 3. The interaction of 8-HQ with $\mathrm{Na}(\mathrm{I})$ Mont has decreased the intensity of the $-\mathrm{OH}$ stretching band (at $\left.3406 \mathrm{~cm}^{-1}\right)$. Between $574 \mathrm{~cm}^{-1}$

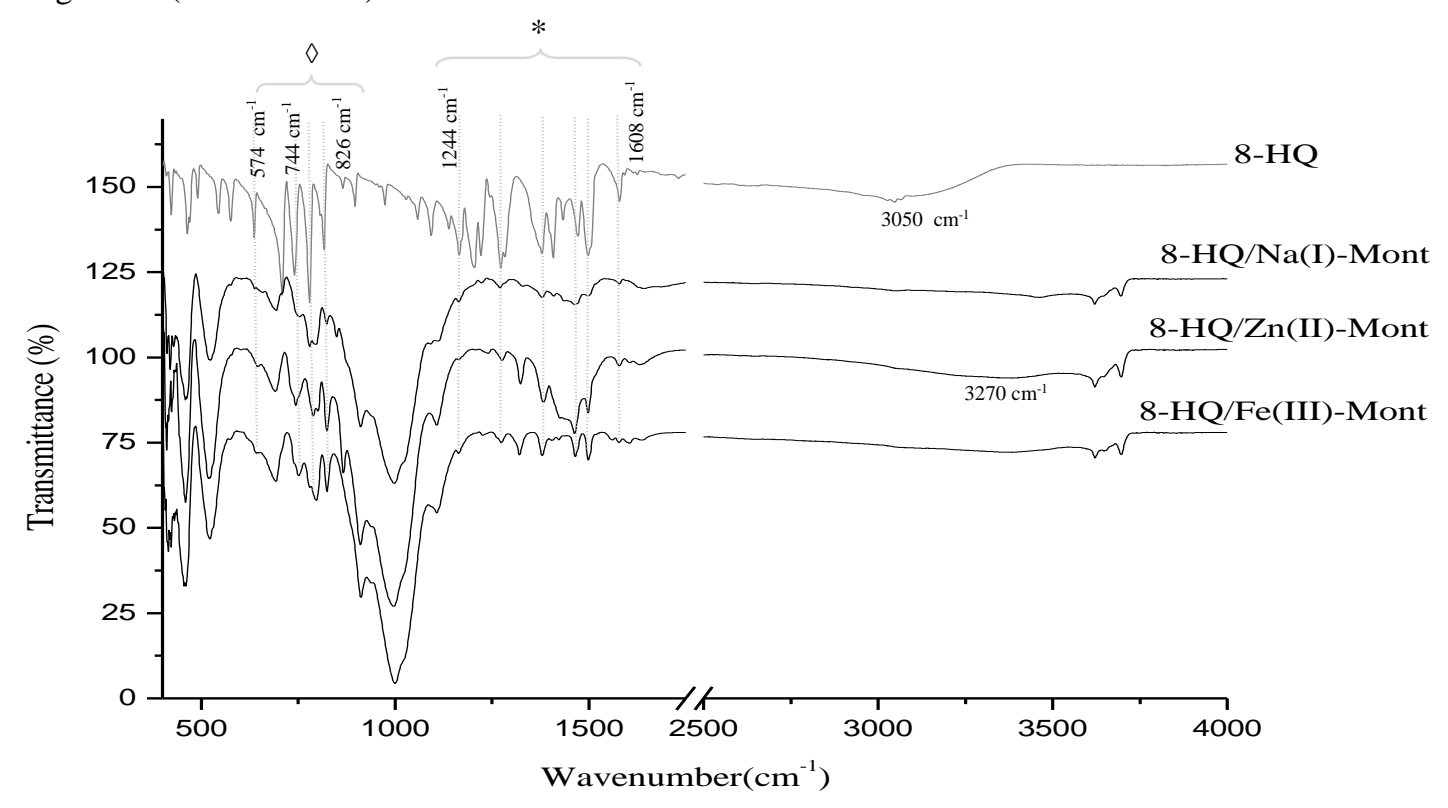

Figure 3. FTIR spectra of hybrids and 8-HQ

In the IR spectrum of 8-HQ/Zn(II)-Mont, the valence band of -OH has shifted from $3406 \mathrm{~cm}^{-1}$ to $3270 \mathrm{~cm}^{-}$ ${ }^{1}$. This shift is due to the exchange of water molecule by $8-\mathrm{HQ}$, to form a complex with zinc cation, and whose $-\mathrm{OH}$ band appears at $3050 \mathrm{~cm}^{-1}$. On both 8 $\mathrm{HQ} / \mathrm{Zn}(\mathrm{II})-$ and $\mathrm{Fe}(\mathrm{III})-\mathrm{Mont}$ spectra, new sharp and medium intensity absorption bands $(*)$ have appeared at the range of 1244- $1608 \mathrm{~cm}^{-1}$. They have been and $826 \mathrm{~cm}^{-1}$, new bands $(\diamond)$ have appeared, corresponding to the skeletal non-planar and inplane bending of 8-HQ. The bending band of $\mathrm{CH}_{\mathrm{ar}}$ has performed at $749 \mathrm{~cm}^{-1}$. Moreover, the stretching vibrations of $\mathrm{C}=\mathrm{C}$ and $\mathrm{C}=\mathrm{N}$ have performed between 1464 and $1490 \mathrm{~cm}^{-1}$ as weak bands (*). 
IR spectra of elaborated hybrids make in evidence the interaction of 8-HQ with exchanged montmorillonites. This interaction could be assigned either as adsorption of 8-HQ on the surface or as its intercalation into the interlayer spaces of the clay.

Comparing between the three IR spectra, the intensity and the number of absorption bands corresponding to 8-HQ appeared on hybrid spectra are higher and clearer on the $\mathrm{Zn}$ hybrid spectrum than on the two others, which may indicate that the interaction between 8-HQ and $\mathrm{Zn}$ (II)-Mont is more significant.

\subsubsection{Characterization of hybrids by PXRD}

The X-ray powder diffractograms of 8-HQ and hybrids are presented in Figure 4. The basal distance of hybrids has shifted from 12.36 to $13.46 \AA$ for 8-HQ/Na(I)-Mont, from 15.11 to $15.33 \AA$ for 8-HQ/Zn(II)-Mont and from 14.86 to $15.78 \AA$ for $8-\mathrm{HQ} / \mathrm{Fe}(\mathrm{III})-\mathrm{Mont}$. Although all peaks of the exchanged montmorillonites appear in the diffractograms of the hybrids, the crystallinity was somewhat decreased since the peaks broadened and their areas increased. Moreover, news peaks have been observed on the diffractograms of the $\mathrm{Zn}$ hybrid at 12.89 $\AA$, 5.53-4.74 $\AA, 3.81$ and $2.76 \AA$. These peaks have been identified by the program X'pertHighScore Plus as Reference Pattern PDF00019-1870 from its database ICDD ${ }^{21}$. They were assigned to the complex Zinc bis-8-quinoline dihydrate $\left[\mathrm{Zn}\left(\mathrm{C}_{9} \mathrm{H}_{6} \mathrm{ON}\right)_{2}\left(\mathrm{H}_{2} \mathrm{O}\right)_{2}\right]$ with monoclinic structure and a space group $\mathrm{P} 2{ }_{1} / \mathrm{c}^{21}$.

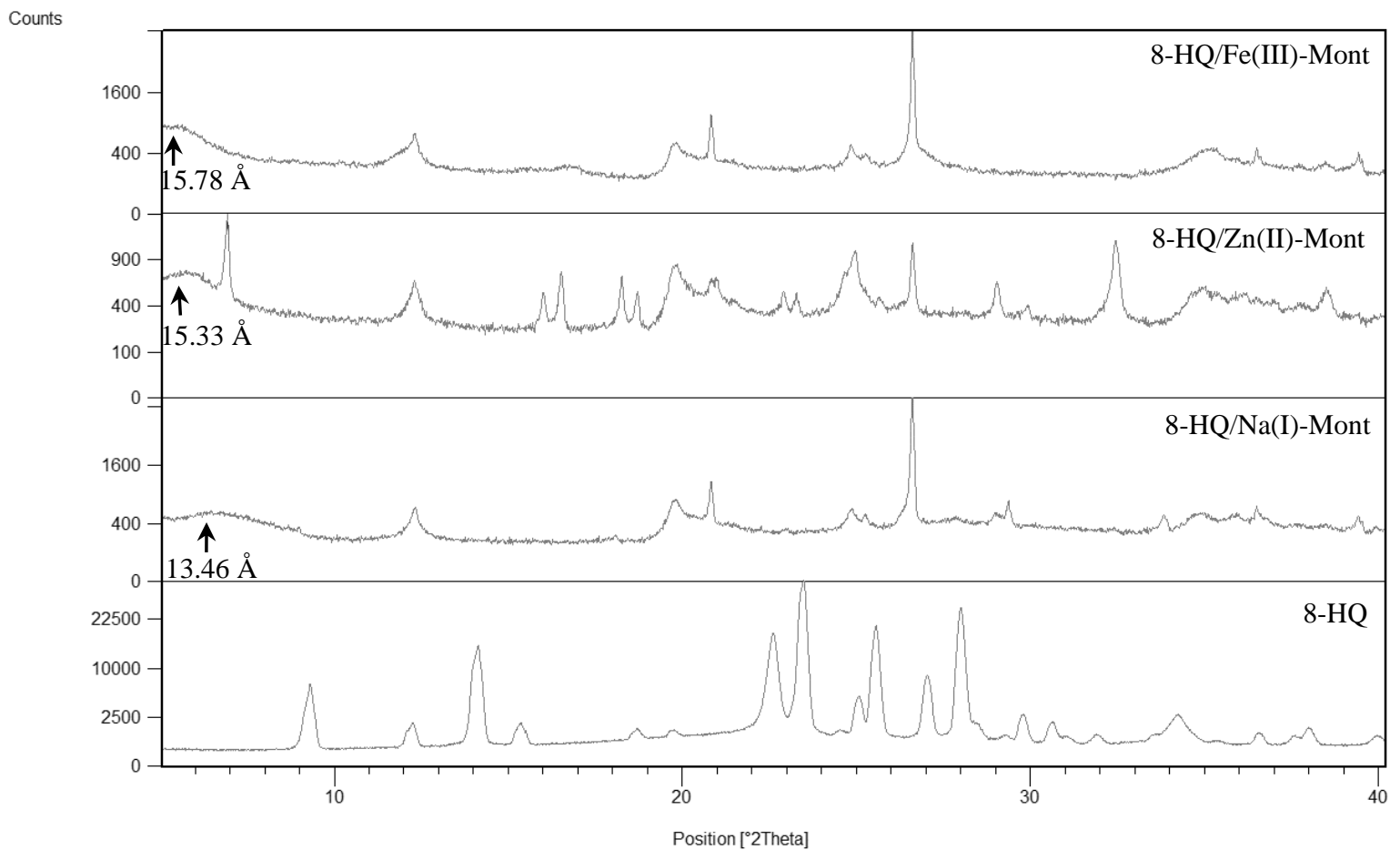

Figure 4. PXRD patterns of $\mathrm{Na}(\mathrm{I})-, \mathrm{Zn}(\mathrm{II})$ and $\mathrm{Fe}(\mathrm{III})$ - hybrids and 8-HQ

\subsubsection{Thermal analysis}

The DSC curves of 8-HQ, exchanged-Mont and the 8HQ hybrids are shown in Figure 5. The 8-HQ curve (Figure 5a) shows two endothermic peaks corresponding respectively to the melting $\left(76^{\circ} \mathrm{C}\right)$ and evaporation $\left(238^{\circ} \mathrm{C}\right)$ of 8 -HQ.

On the $\mathrm{Na}(\mathrm{I})$-Mont curve (Figure 5b), two endothermic peaks are observed at 96 and $542^{\circ} \mathrm{C}$. The first one is assigned to the evaporation of the adsorbed molecule of water while the second is attributed to the dihydroxylation of $-\mathrm{OH}$ groups of montmorillonite. However, after interaction with 8-HQ, a third endothermic peak appears at $235^{\circ} \mathrm{C}$. It is ascribed to the removal of 8-HQ weakly adsorbed on the surface. The two other bands shift respectively to a lower temperature $\left(87 \text { and } 510^{\circ} \mathrm{C}\right)^{22}$. The melting of $8-\mathrm{HQ}$, adsorbed on the surface of the hybrid, seems to be the reason of the decrease of temperature of the first peak (from $96^{\circ} \mathrm{C}$ to $87^{\circ} \mathrm{C}$ ). 

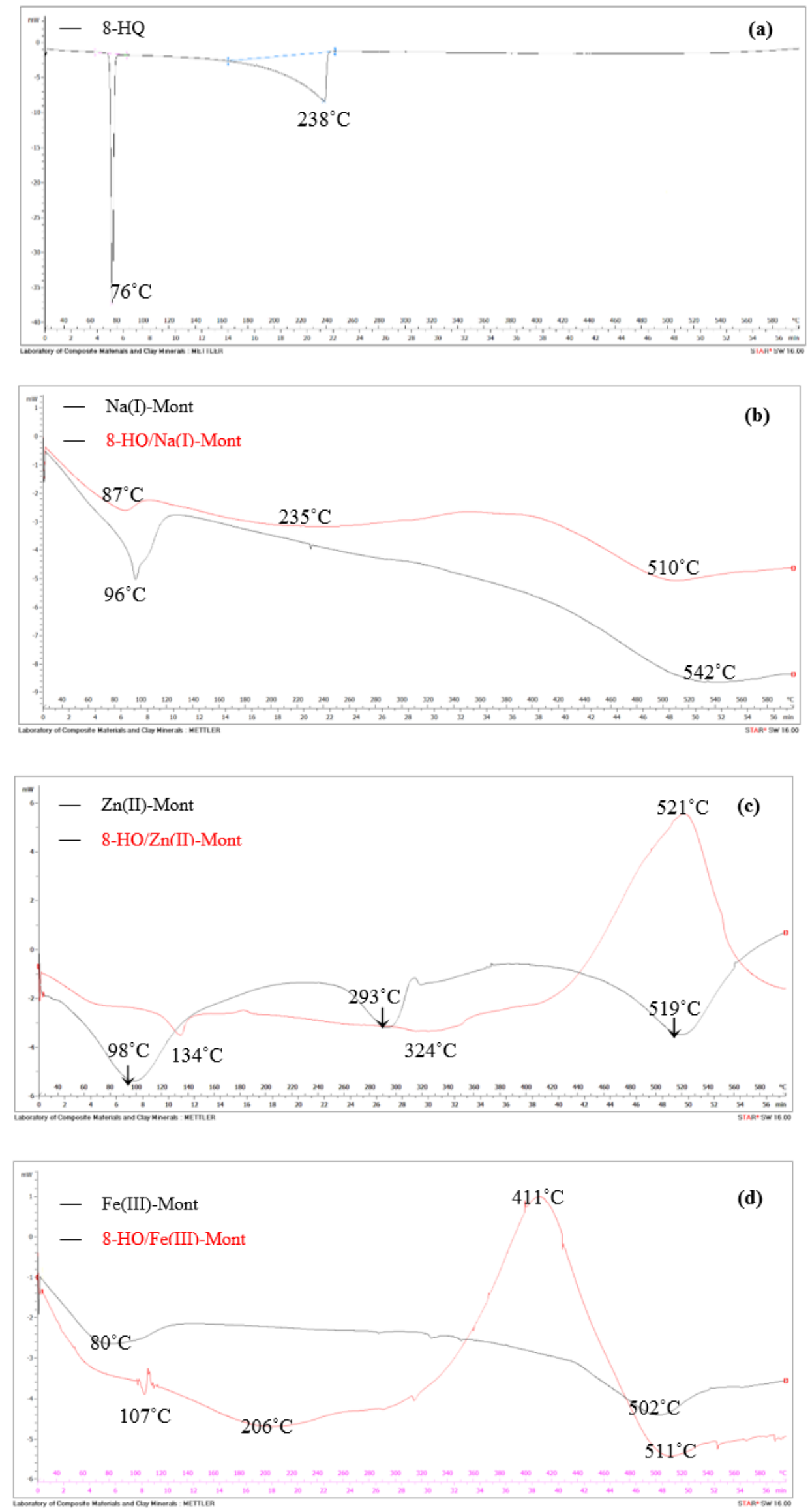

Figure 5. DSC curves of 8-HQ, exchanged clays and their hybrids: (a)8-HQ, (b)Na(I)-Mont and its hybrid, (c) $\mathrm{Zn}$ (II)-Mont and its hybrid, (d) Fe(III)-Mont and its hybrid 


\subsubsection{Luminescence study}

To study the luminescence properties of montmorillonite hybrids (8-HQ/Na(I)-, Zn(II)- and Fe(III)-Mont), the fluorescence spectroscopic study has been investigated under excitation of $360 \mathrm{~nm}$ (wavelength of the absorption of 8-HQ), in the same condition as our previous work to compare the luminescence efficiency between hybrids prepared either by solid-solid reaction or by liquid-solid extraction at different $\mathrm{pH}$ and concentration ${ }^{12}$. Figure 6 shows the emission bands of the three elaborated hybrids and 8-HQ. The original shape of the emission band corresponding to 8-HQ has changed after its inclusion in exchanged montmorillonites. These latter have no light emission, as well as $\mathrm{Na}$ and $\mathrm{Fe}$ hybrids. It has been reported that the free 1:1 complex of Liq and the free 3:1 complex of Alq3 (q: 8-hydroxyquinoline) exhibit high emission light, but when these complexes are formed in-situ the interlayer space of montmorillonite, their light emissions are quenched considerably 14-15,24-26. Singh et al. ${ }^{24}$ have reported that every modification in the complex structure of $\left(\mathrm{Alq}_{3}\right)$ by mixing with other ligand or insertion of the electron-donating group on 2 positions in quinolone change the emission color. In parallel, Schmitz group ${ }^{25}$ has accounted for the bluelight emission of $\mathrm{Li}(8-\mathrm{HQ})$ in OLEDs.
In the case of $\mathrm{Zn}$ hybrid, a very intensive emission band has been observed. It was not possible to record it only after the reduction of its intensity to $1 \%$. The maximum of emission has shifted to $510 \mathrm{~nm}$, revealing that the $\mathrm{Zn}$ hybrid is emitting a green color. In brief, unlike $\mathrm{Na}$ and $\mathrm{Fe}$ hybrids who quenched the luminescence, the bivalent complex [ $\mathrm{Zn}(\mathrm{II})$. $\left.(8-\mathrm{HQ})_{2}\right]^{2+}$ enhances the emission significantly, whether prepared via solid-solid reaction or extraction from aqueous solution ${ }^{12}$.

In the case of zinc(II) quinolate, many researchers have described the obtain of blue, green and white light emission following the discovery of its enhanced emission ${ }^{13,26}$. To explain that difference in light emission between the multivalent complexes of 8-HQ shielded between silicate layers, Sapochak et al. ${ }^{27}$ have demonstrated that the difference of luminescence intensity between mono- and bi-ligand complexes of 8-HQ is influenced not by the kind of cation (mono- or bi-valent) but by the number of ligand (8-HQ) in the complexes. However, Fe(III) has been reported to form a trivalent complex with 8 -HQ ${ }^{23}$, which means the number of 8-HQ coordinated with the cation is higher. In this case, other parameters may be taken into consideration as the type of sphere electron transfer (inner or outer), coordination and structural arrangements.

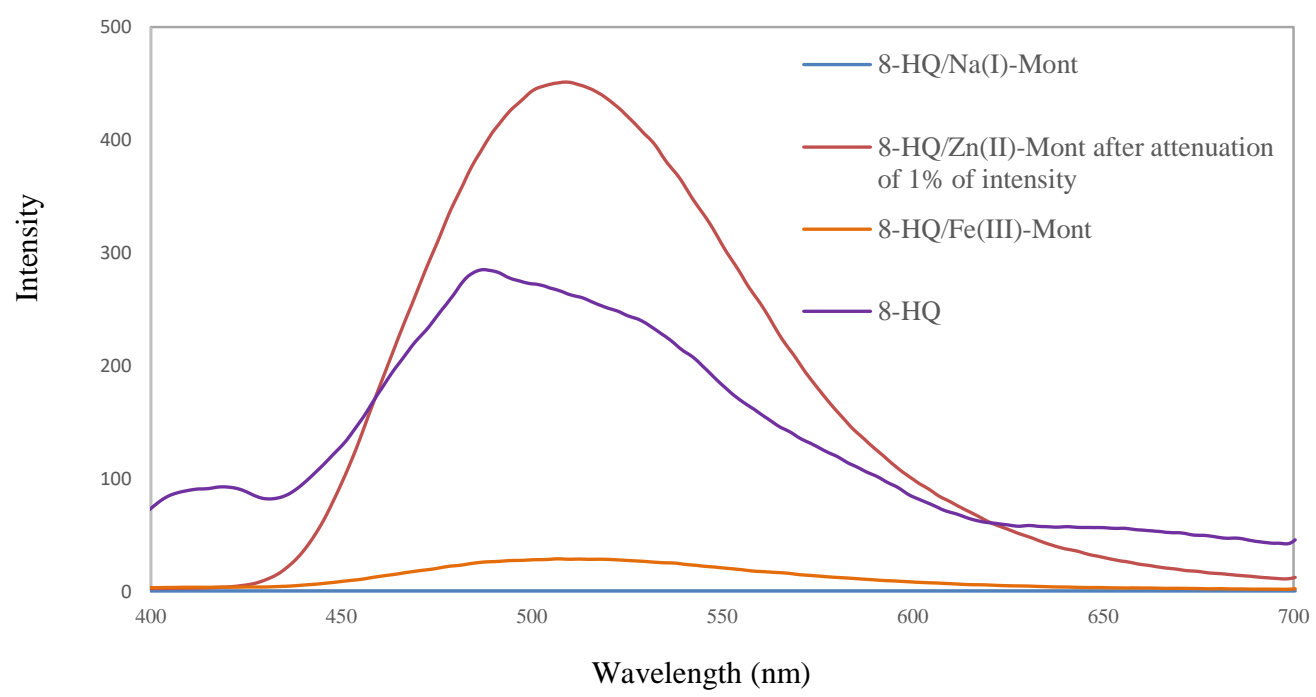

Figure 6. Emission bands of hybrids and 8-HQ

\subsubsection{Zeta potential measurement}

Three samples of each compound (natural clay, exchanged montmorillonites: $\mathrm{Na}(\mathrm{I})-, \mathrm{Zn}(\mathrm{II})$ and Fe(III)-Mont, and hybrids: 8-HQ/Na(I)-, Zn(II)- and Fe(III)-Mont) were studied. All showed a negative potential charge (ZP) ranging from $-47.2 \mathrm{mV}$ to $-5.97 \mathrm{mV}$, and therefore no point zero charge (pzc) could be found although the zeta charge decreased from acidic $\mathrm{pH}$ to basic $\mathrm{pH}$. The comparison between exchanged-Mont and hybrids, shows the latter less negative since the organic molecule 8-HQ is protonated in an acidic medium which explains the increase of charge at the range of $\mathrm{pH}=2-6$ (Figure 7). 

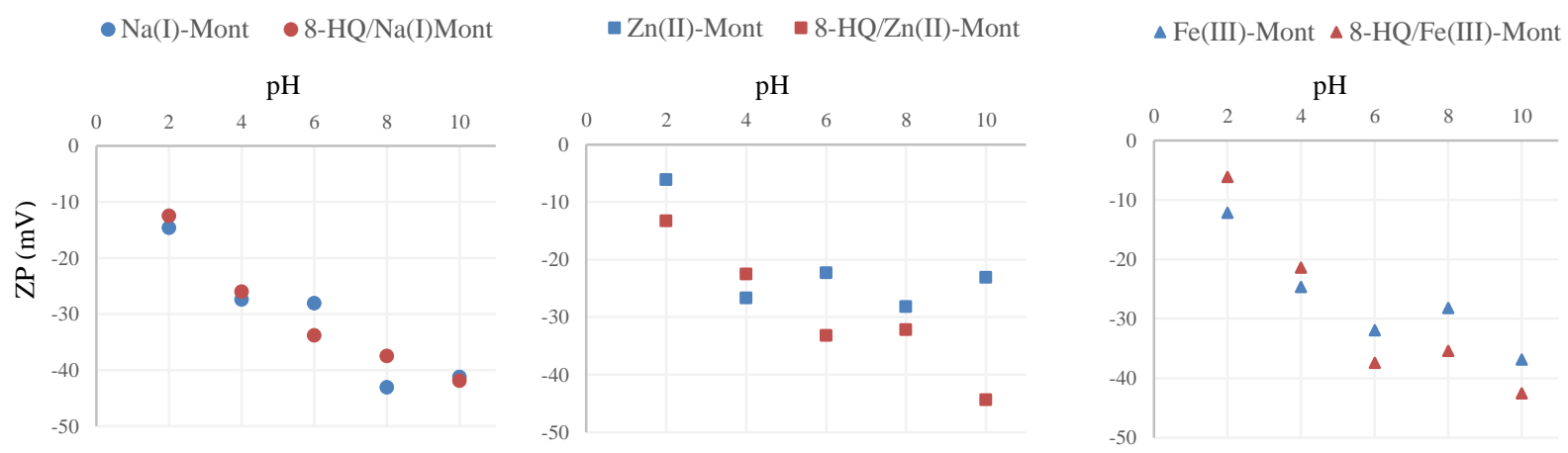

Figure 7: Zeta Potential (ZP) of exchanged Montmorillonites and their hybrids.

\subsubsection{Sorption of methylene blue MB by hybrids}

As the Zeta charge of hybrids is negative, the aqueous solution used here contains methylene blue (MB) as a cationic dye. The adsorption yields of MB $(\mathrm{T}(\%))$ calculated after 1 day, and after 1 month of sedimentation are presented in Figure 8. The T of MB on $\mathrm{Na}(\mathrm{I})$ - and $\mathrm{Zn}(\mathrm{II})$ - hybrids is vital after 1 day (97.5 and $98.4 \%$, respectively). While in the case of $\mathrm{Fe}(\mathrm{III})$ hybrid, $\mathrm{T}$ is less significant $(38.5 \%)$, but become higher after 1 month of sedimentation (87.0\%). Although this improvement, it remains still inferior to $\mathrm{Na}(\mathrm{I})$ - and $\mathrm{Zn}(\mathrm{II})$-hybrids for which $\mathrm{T}(\%)$ increases slightly, to $99.4 \%$ and $99.2 \%$, respectively. These results are prominent in water treatment, namely with $\mathrm{Na}$ - and $\mathrm{Zn}$ - hybrids. The lower sorption ability of Fehybrid could be assigned to the formation of $\mathrm{FeO}(\mathrm{OH})$ as described above through PXRD study. Comparing with $\mathrm{Fe}(\mathrm{III})-\mathrm{Mont}$, it has been reported that the sorption of MB by Fe-Mont is successful $(100 \%$ adsorbed) in $7 \mathrm{~min}$ and at $\mathrm{pH}=7$ and the adsorption follows the pseudo-first-order kinetics ${ }^{28}$. Moreover, it has been exposed that $\mathrm{Fe}(\mathrm{III})-$ Mont could be recovered after the reaction by centrifugation from the degraded MB dye solution ${ }^{28}$.

Shao et al. ${ }^{29}$ have studied the adsorption of two dyes: orange acid and light turquoise blue dye from wastewater by 8-hydroxyquinoline modified bentonite, at different $\mathrm{pH}$ values, concentration, stirring speed and sedimentation time. They reported the best discoloration rate was $88 \%$. However, with our Na- and $\mathrm{Zn}$ - hybrids, the discoloration is almost $100 \%$. This high adsorption yield was also reported with another adsorbent materiel such as silica gel supported dinitro calix[4]arene cage (DNCC) via using batch adsorption process. It has been reported that DNCC exhibited a high affinity towards $\mathrm{MB}$ molecules in aqueous media $\left(Q_{\text {ads }}=212.770 \mathrm{mg} \cdot \mathrm{g}^{-1}\right)$ and the adsorption was exothermic and spontaneous and well fit for the second-order kinetic model ${ }^{30}$. Han et al. ${ }^{31}$ from their side have reported the high efficiency of activated carbon prepared by thermal activation of eucalyptus residue impregnated with phosphoric acid $\left(\mathrm{Q}_{\mathrm{ads}}(\mathrm{MB})=977 \mathrm{mg} \cdot \mathrm{g}^{-1}\right)$. Its ability to adsorb MB has been assigned to the large specific surface area and the high concentration of acidic functional groups.

Moreover, while following the absorbance of the liquid phase by UV-visible spectrometer to calculate the rate of discoloration, no new band of absorption was observed, meaning that the complex of 8-HQ was maintained between silicate layers and no exchange between 8-HQ complexes and MB has taken place.

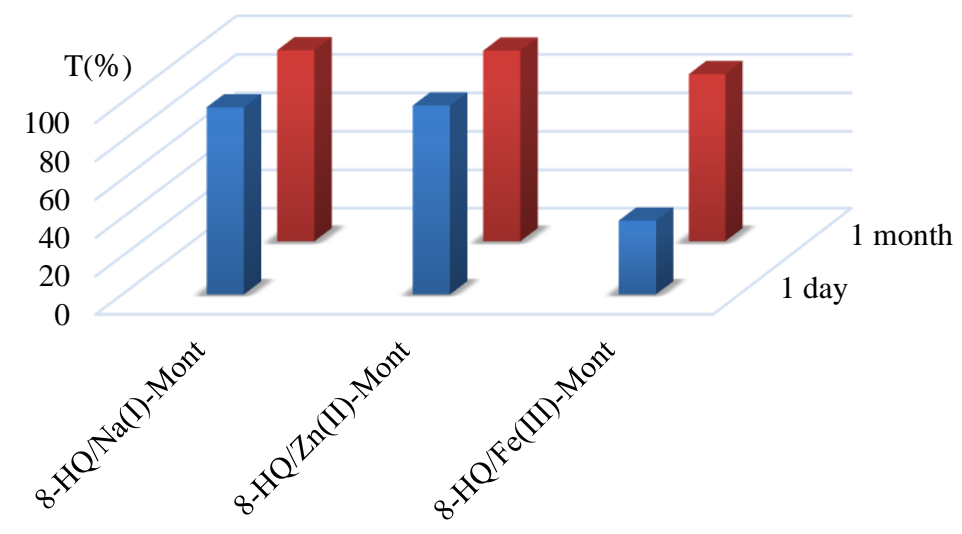

Figure 8. Adsorption yield $\mathrm{T}(\%)$ of $\mathrm{MB}\left(\mathrm{C}_{\mathrm{MB}}=200 \mathrm{mg} \cdot \mathrm{L}^{-1}\right)$ after $1^{\text {st }}$ day and after 1 month of sorption

After MB solution treatment, each new multiple hybrid MH (Hybrid+MB) was filtered off and dried. Their PXRD patterns are shown in Figure 9. All peaks were broadened and the basal distances $\mathrm{d}_{001}$ shifted to
$15.32 \AA ̊, 16.61 \AA ̊$ and $16.99 \AA ̊$ in Na(I)-, Zn(II)- and $\mathrm{Fe}(\mathrm{III})$-hybrids, respectively. The shift $\delta(\delta=$ $\left.\mathrm{d}_{001}(\mathrm{MH})-\mathrm{d}_{001}(\mathrm{H})\right)$ is equal to $1.86 \AA$ for $\mathrm{Na}-\mathrm{MH}, 1.28$

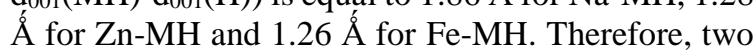


conclusions can be drawn from these results: the first is that the dye $\mathrm{MB}$ is intercalated onto the interlayer space of hybrids, and the second that MB molecules seem to be intercalated as bilayered and parallel to silicate layers in the case of $\mathrm{Na}-\mathrm{MH}$, while monolayered and deviated in the case of $\mathrm{Zn}-$ and $\mathrm{Fe}-\mathrm{MH}$.

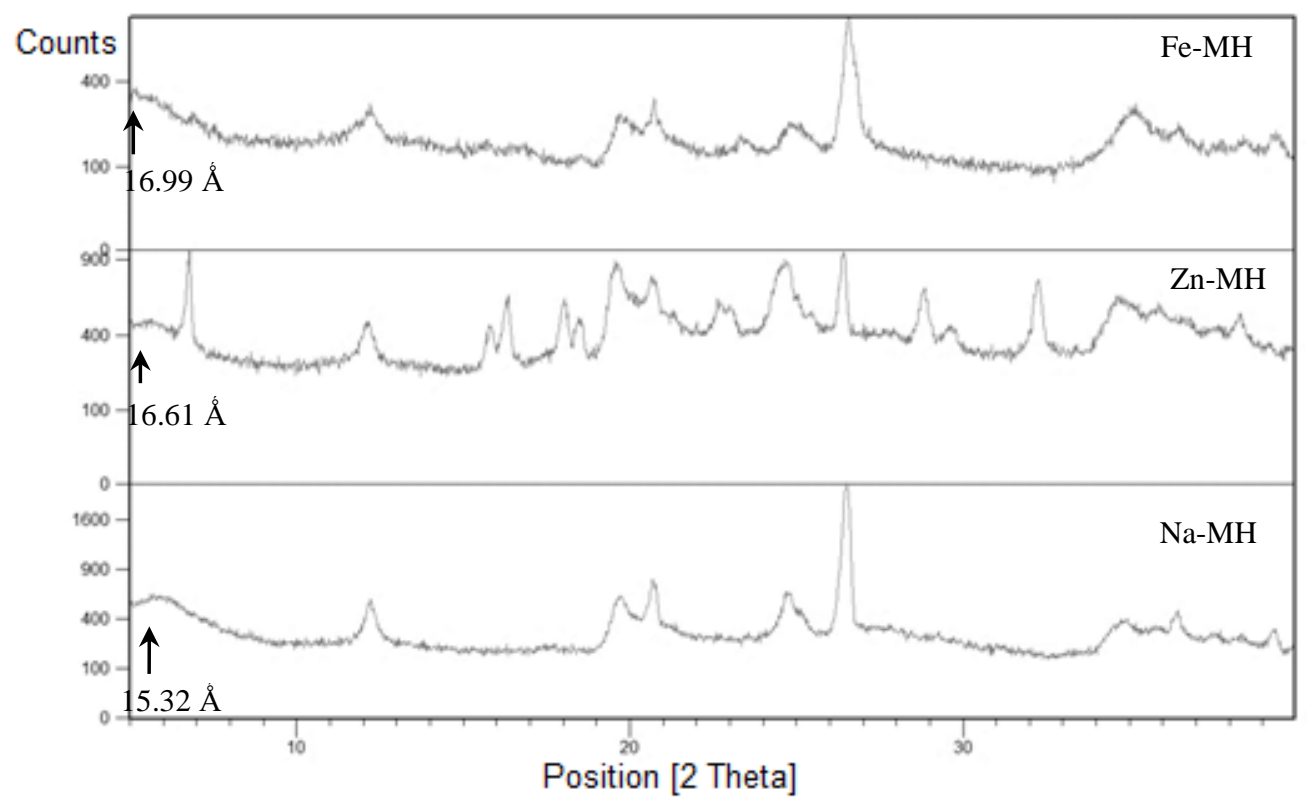

Figure 9. PXRD patterns of multi-hybrid (MH) after sorption of $\mathrm{MB}$ by $\mathrm{Na}(\mathrm{I})-, \mathrm{Zn}(\mathrm{II})$ - and Fe(III)-hybrids

\section{Conclusion}

Green synthesis of hybrids $(\mathrm{H})$ based on 8hydroxyquinoline (8-HQ) and $\mathrm{Na}(\mathrm{I})-, \mathrm{Zn}(\mathrm{II})$ - and Fe(III)-Mont has been achieved via solid-solid reaction. The elaborated hybrids have been characterized by X-ray diffraction and FTIR. New bands at the ranges of $1244-1608 \mathrm{~cm}^{-1}$ and $574-826$ $\mathrm{cm}^{-1}$ have appeared on IR spectra, and assigned to 8HQ groups. The basal distance $\mathrm{d}_{001}$ have shifted to higher values (Na-H: $13.46 \AA$; Zn-H: $15.33 \AA$; Fe$\mathrm{H}: 15.78 \AA$ ) due to the complexation of 8-HQ with respectively $\mathrm{Na}^{+}, \mathrm{Zn}^{2+}$ and $\mathrm{Fe}^{3+}$ inside the interlayer spaces.

The SEM analysis of exchanged-Mont(s) has shown circular particles with different size. A better continuity for Fe(III)-Mont was observed. The Zeta measurement has shown the negative charge of exchanged-Mont(s) and their decrease from acidic to basic medium. The intercalation of 8 -HQ seems to increase the charge slightly, but still, no pzc has been found.

In the thermal analysis, the DSC patterns have shown that hybrids are thermally more stable than exchanged montmorillonites and even than free complexes of similar compositions (8-HQ and $-\mathrm{Na}^{+},-\mathrm{Zn}^{2+},-\mathrm{Fe}^{3+}$ ). As luminescence application, the $\mathrm{Zn}$ hybrid has made in evidence its green and intense emission.

$\mathrm{Na}$ and $\mathrm{Zn}$ hybrids have shown their efficiency ( $\mathrm{T}$ is almost 100\%) in MB sorption from aqueous solution, and the PXRD analysis has revealed the inclusion of MB onto silicate layers via hydrogen bonding interaction with 8-HQ. In further experiments, optimum sorption condition was specified by the changing of different parameters such as initial $\mathrm{MB}$ concentration, $\mathrm{pH}$, contact time and temperature.

\section{References}

1- R. Zhu, Q. Zhou, J. Zhu, Y. Xi, H. He, OrganoClays As Sorbents of Hydrophobic Organic Contaminants: Sorptive Characteristics and Approaches to Enhancing Sorption Capacity, Clays Clay Miner., 2015, 63, 199. https://doi.org/10.1346/CCMN.2015.0630304.

2- Q. Wang, Y. Wang, L. Chen, A green composite hydrogel based on cellulose and clay as an efficient absorbent of colored organic effluent, Carbohydrate Polymers, 2019, 210, 314-321. https://doi.org/10.1016/j.carbpol.2019.01.080.

3- A. A. Adeyemo, I. O. Adeoye, O. S. Bello, Adsorption of dyes using different types of clay: a review, Appl Water Sci., 2017, 7, 543-568. https://doi.org/10.1007/s13201-015-0322-y.

4- F. Ayari, E. Srasra, M. Trabelsi-Ayadi, Retention of organic molecule quinalizarin" by bentonitic clay saturated with different cations, Desalination, 2007, 20, 499-506. https://doi.org/10.1016/j.desal.2006.03.578.

5- M. Lackovičová, T. Baranyaiová, J. Bujdák, The chemical stabilization of methylene blue in colloidal dispersions of smectites, Applied Clay Sciences, 2019, 181, 105222. https://doi.org/10.1016/j.clay.2019.105222.

6- T. S. Anirudhan, M. Ramachandran, Adsorptive removal of basic dyes from aqueous solutions by surfactant modified bentonite clay (organoclay): 
Kinetic and competitive adsorption isotherm, Proces. Saf. Env. Protect., 2015, 95, 215-225. https://doi.org/10.1016/j.psep.2015.03.003.

7- A. H. Jawad, A. S. Abdulhameed, Mesoporous Iraqi red kaolin clay as an efficient adsorbent for methylene blue dye: Adsorption kinetic, isotherm and mechanism study, Surfaces and Interfaces, 2020, 18, 100422. https://doi.org/10.1016/j.surfin.2019.100422.

8- A. S. Abdulhameed, A. T. Mohammad, A. H. Jawad, Application of response surface methodology for enhanced synthesis of chitosan tripolyphosphate/ $\mathrm{TiO}_{2}$ nanocomposite and adsorption of reactive orange 16 dye, Journal of Cleaner Production, 2019, 232, 43-56. https://doi.org/10.1016/j.jclepro.2019.05.291.

9- A. S. Abdulhameed, A. T. Mohammad, A. H. Jawad, Modeling and mechanism of reactive orange 16 dye adsorption by chitosanglyoxal/ $/ \mathrm{TiO}_{2}$ nanocomposite: Application of response surface methodology, Desalination and Water Treatment, 2019, 164 346-360. https://doi.org/10.5004/dwt.2019.24384.

10-F. Ayari, M. T. Ayadi, Inorganic and organic smectite for synthetic and real textile water treatment. Optical and luminescence properties, Desalination and Water Treatment, 2018, 125 , 47-60. https://doi.org/10.5004/dwt.2018.22696.

11-B. Erdem, A. Özcan, Adsorption and solid-phase extraction of 8-hydroxyquinoline from aqueous solutions by using natural bentonite, Appl. Surf. Sci., 2010, 256, 5422-5427. https://doi.org/10.1016/j.apsusc.2009.12.126.

12-B. Mellah, D. Sall, I. Msaddak, E. Srasra, Intercalation of 8-hydroxyquinoline into $\mathrm{Na}(\mathrm{I})$ and $\mathrm{Zn}(\mathrm{II})-\mathrm{Tunisian}$ montmorillonites: characterization and luminescence properties of elaborated hybrids, J. Inclus. Phenom. Macrocycl. Chem., 2019, 94, 309-318. https://doi.org/10.1007/s10847-018-0826-9.

13-N. Khaorapaponga, M. Ogawa, In situ formation of bis(8-hydroxyquinoline) zinc(II) complex in the interlayer spaces of smectites by solid-solid reactions, Journal of Physics and Chemistry of Solids , 2008, 69, 941-948. https://doi.org/10.1016/j.jpcs.2007.10.092.

14-N. Khaorapapong, M. Ogawa, Solid-state intercalation of 8-Hydroxyquinoline into $\mathrm{Li}(\mathrm{I})$-, $\mathrm{Zn}$ (II)- and Mn(II)-montmorillonites, Applied Clay Science, 2007, 35, 31-38. https://doi.org/10.1016/j.clay.2006.08.003.

15-N. Khaorapapong, K. Kuroda, M. Ogawa, Intercalation of 8-hydroxyquinoline into Alsmectites by solid-solid reactions, Clays and Clay Minerals, 2002, 50, 428-434. https://doi.org/10.1346/000986002320514154.

16-P. Pimchan, N. Khaorapapong, M. Ogawa, Preparation of a series of group XIII metalquinolate complexes in natural and synthetic smectites, Applied Clay Science, 2011, 54, 3-4, 287-291.

https://doi.org/10.1016/j.clay.2011.09.002.
17-F. Bergaya, G. Lagaly, General introduction: clays, clay minerals, and clay science, Dev. Clay Sci., 2006, 1, 1-18. https://doi.org/10.1016/S1572-4352(05)01001-9.

18-J. Manjanna, T. Kozaki, S. Sato, Fe(III)montmorillonite: Basic properties and diffusion of tracers relevant to alteration of bentonite in deep geological disposal, Applied Clay Science, 2009, 43, 208-217. https://doi.org/10.1016/j.clay.2008.09.007.

19-J. Bishop, J. Madejová, P. Komadel, H. Fröschl, The influence of structural $\mathrm{Fe}, \mathrm{Al}$ and $\mathrm{Mg}$ on the infrared $\mathrm{OH}$ bands in spectra of dioctahedral smectites, Clay Minerals, 2002, 37, 607-616. https://doi.org/10.1180/0009855023740063.

20-Y. E. Dolaksiz, F. Temel, M. Tabakci, Adsorption of phenolic compounds onto calix[4]arene-bonded silica gels from aqueous solutions, Reactive and Functional Polymers, 2018, 126, 27-35. https://doi.org/10.1016/j.reactfunctpolym.2018.0 3.003 .

21-L. Lynne, J. R. Merrit, R. T. Cady, B. W. Miundy, The Crystal Structure of Zinc 8Hydroxyquinolinate Dihydrate, ActaCrystallogr., 1954, 7, 473. https://doi.org/10.1107/S0365110X54001491.

22-I. A. Pastre, D. N. Oliveira, A. B. S. Moitinho, G. R. de Souza, E. Y. Ionashiro, F. L. Fertonani, Thermal behavior of intercalated 8hydroxyquinoline (oxine) in montmorillonite clay, J. Therm. Analy. Calom., 2004, 75, 661669. https://doi.org/10.1023/B:JTAN.0000027160.193 88.0c.

23-B. T. Franzin, C. P. Lupi, L. A. Martins, F. C. Guizellini, C. C. Marques dos Santos, I. A. Pastre, F. L. Fertonani, Thermal and electrochemical studies of Fe(III) organophilic montmorillonite, J. Therm. Anal. Calorim., 2018, 131, 713-723. https://doi.org/10.1007/s10973017-6327-z.

24-D. Singh, V. Nishal, S. Bhagwan, R. K. Saini, I. Singh, Electroluminescent materials: Metal complexes of 8-hydroxyquinoline - A review." Materials \& Design, 2018, 156, 215228. https://doi.org/10.1016/j.matdes.2018.06.0 $\underline{36}$.

25-C. Schmidt, H. W. Thelakkat, Lithium-Quinolate complexes as emitter and interface materials in organic light-emitting diodes, Chem Mater., 2000, 12, 3012-19. https://doi.org/10.1021/cm0010248

26-F. Dumur, L. Beouch, M. A. Tehfe, E. Contal, M. Lepeltier, G. Wantz, B. Graff, F. Goubard, C. R. Mayer, J. Lalevée, D. Gigmes, Low-cost zinc complexes for white organic light-emitting devices, Thin Solid Films, 2014, 564, 351-60. https://doi.org/10.1016/j.tsf.2014.06.006.

27-L. S. Sapochak, E. F. Benincasa, R. S. Schofield, J. L. Baker, K. K. C. Riccio, D. Fogarty, H. Kohlmann, K. F. Ferris, P. E. Burrows, 
Electroluminescent zinc(II) bis(8-

hydroxyquinoline): structural effects on electronic states and device performance, $\mathrm{J}$. Am.Chem. Soc., 2002, 124, 6119-6125. https://doi.org/10.1021/ja0201909.

28-M. Vinuth, H. S. B. Naik, M. M. Mahadevaswamy, M. C. Prabhakara, Environmentally benign $\mathrm{Fe}(\mathrm{III})$-montmorillonite for rapid adsorption of methylene blue dye in aqueous medium under ambient conditions, Fash. Text., 2017, 4, 8. https://doi.org/10.1186/s40691017-0087-z.

29-H. Shao, N. Cao, H. Xiao, Adsorption properties of dyeing wastewater on 8-hydroxyquinoline modified bentonite", Applied Mechanics and
Materials, 2011, 71-78 1118-1122.

https://doi.org/10.4028/www.scientific.net/AMM .71-78.1118.

30-F. Temel, M. Turkyilmaz, S. Kucukcongar, Removal of methylene blue from aqueous solutions by silica gel supported calix[4]arene cage: Investigation of adsorption properties, European Polymer Journal, 2020, 125, 109540. https://doi.org/10.1016/j.eurpolymj.2020.109540.

31-Q. Han, J. Wang, B. A. Goodman, J. Xie, Z. Liu, High adsorption of methylene blue by activated carbon prepared from phosphoric acid-treated eucalyptus residue, Powder Technology, 2020, 366, 239-248.

https://doi.org/10.1016/j.powtec.2020.02.013. 